\title{
Lung function of office workers exposed to humidifier fever antigen
}

\author{
I ASHTON, A T AXFORD,* C BEVAN, AND J E COTES $\dagger$ \\ From the MRC Pneumoconiosis Unit, Llandough Hospital, Penarth, S Glam CF6 $1 X W$, UK
}

ABSTRACT Office workers who became sensitised to antigens derived from humidifier sludge developed episodes of fever, malaise, and other symptoms, including polyuria and mild chest tightness. The episodes usually occurred on a Monday evening and were to some extent dose-related. Lung function was assessed over a day shift on two occasions, including one after which almost all the susceptible subjects developed symptoms. The symptoms were preceded by a $6 \%$ reduction in forced expiratory volume and vital capacity, a corresponding increase in residual volume, and a reduction in flow rate after $75 \%$ vital capacity had been expired. There were no changes in peak expiratory flow, forced expiratory flow at $50 \%$ of vital capacity, or transfer factor. In some subjects the transfer factor was apparently reduced 36 hours later, but for this there may have been another explanation. The physiological features were considered to reflect narrowing of small airways in the lung. The changes, however, were minimal and not the main cause of the symptoms. A feature of the episode was the severity of the constitutional symptoms despite the low airborne dust levels.

Illness associated with sensitisation to microorganisms growing in an air conditioning or humidifier system may take several forms. ${ }^{12}$ In one such episode among office workers pyrexia and malaise were the main features, and an immunologically similar illness has recently been reported among staff in a hospital operating theatre. ${ }^{3}$

The present episode occurred among office workers whose premises adjoined a factory making cellulose products. No illness was observed among the factory population. The industrial process required a supply of warm moist air, which was delivered from a humidifier situated in the roof space above the office and separated from it by a suspended ceiling.

Steam leaking into the roof space wetted cellulose dust and provided a culture medium for microorganisms; small quantities of resulting antigenic material entered the offices and caused an immunological reaction in a few subjects.

Among the organisms responsible was a water-

\footnotetext{
Present addresses:

*Bronglais General Hospital, Aberystwyth, Dyfed.

†University Department of Occupational Health and

Hygiene, Newcastle upon Tyne.

Received 22 April 1980

Accepted 2 May 1980
}

borne amoeba related to Naegleria gruberi; this aspect is reported elsewhere. ${ }^{45}$ The present paper reports some of the clinical and physiological features; these are notable in that compared with the other episodes, cited above, the respiratory abnormality was apparently both incidental to the main illness and did not primarily affect the gas exchanging function of the lung.

\section{Subjects and methods}

The subjects were all the workers in the office- 31 men and 16 women. At the start of the present study they were assessed clinically, a detailed history of recent symptoms was obtained, and forced expiratory volume $\left(\mathrm{FEV}_{1}\right)$ and vital capacity $(\mathrm{FVC})$, using a McDermott bellows spirometer, ${ }^{6}$ and peak expiratory flow rate (PEFR), using a Wright peak flow meter, were measured. These measurements were made subsequently on several occasions. In addition, on one Monday and Tuesday, flow volume curves were recorded using the spirometer coupled to a differentiator and Bryant X-Y recorder, and measurements were made of the transfer factor $\left(\mathrm{Tl}^{\prime}\right)$ by the single breath carbon monoxide method, using a respirameter. The lung volume during breath holding $\left(\mathrm{VA}^{\prime}\right)$ was estimated from the concurrent dilution of helium present in the test gas mixture. 
From these measurements the $\mathrm{Kco}\left(\mathrm{Tl}^{\prime} \div \mathrm{VA}^{\prime}\right)$ and the residual volume $\left(\mathrm{RV}^{\prime}\right)$ were also calculated. The details of the procedures including the method for correcting volume from ambient to body temperature, the sources of reference values, and the criteria as to what constituted a technically satisfactory result are given elsewhere. ${ }^{7}$ In the statistical analysis the probability level of $5 \%$ was accepted as significant.

\section{Results}

Eleven subjects reported recurrent episodes of illness having common features, which we believe to be typical of the present incident. The symptoms usually developed progressively starting in the afternoon. They were mostly very mild, but in a few subjects the symptoms became more pronounced during recurrences. Initially, there was usually a feeling of being cold, often with shivering, and this was followed by fever, up to $39.4^{\circ} \mathrm{C}$, aching limbs, headache, and chest tightness characterised by a feeling of not being able to take a deep breath. Two subjects commented on their breathing being shallow and rapid. One experienced breathlessness. There was no cough, phlegm, or wheeze. Increased frequency of

Table 1 Mean values for ventilatory capacity in 47 (31 male, 16 female) office workers

\begin{tabular}{lllllll}
\hline & \multicolumn{2}{l}{ Men } & & \multicolumn{2}{l}{ Women } \\
\cline { 2 - 3 } \cline { 5 - 6 } \cline { 5 - 6 } & $O$ & $E$ & & $O$ & $E$ \\
\hline Forced expiratory volume (I) & 3.90 & 3.84 & & 2.91 & 2.89 \\
Forced vital capacity (I) & 4.86 & 4.74 & & 3.40 & 3.63 \\
\hline
\end{tabular}

$\mathrm{O}=$ observed. $\mathrm{E}=$ expected. micturition or increased urine formation was commented on by four subjects; on more than one occasion this led to the subject making an unscheduled stop when driving home by car despite not having drunk recently. The symptoms disappeared overnight, but next morning the subjects sometimes felt lethargic and weak and took the day off work to recover. In addition to these subjects with consistent histories, there were others who reported various symptoms, of which at least some appeared to be of functional origin.

On a Tuesday in October the mean values for $F V_{1}$ and FVC for 46 out of the 47 subjects were found to be nearly identical with the reference values (table 1); the single exception was a man who had had an operation for replacement of a valve in the heart. On the morning and afternoon of the following Monday, after the office had been closed for the weekend, 18 of these subjects were seen again. They comprised all who reported symptoms that apparently related to work in the office; 11 reported experiencing features of the syndrome described above (group A) and nine thought that they were affected but the evidence was not convincing (group B). Complete physiological information was obtained on 15. Table 2 summarises personal details, the serum precipitin reactions against humidifier sludge or acanthamoeba antigen, and the results of the lung function tests. The initial values for ventilatory capacity at the start of the day in both groups were nearly identical with those obtained previously. The changes over the working day in the group A subjects included significant reductions in $\mathrm{FEV}_{1}, \mathrm{FVC}$, and flow rate after $75 \%$ of vital capacity had been expired (FEF $75 \%$ ) and an increase in the residual volume. There was no significant change in the PEFR, the

Table 2 Mean values for age, height, and weight, also for lung function on a Monday after office had been shut for weekend (for abbreviations see text). (Numbers of subjects whose serum reacted to humidifier sludge or acanthamoeba antigen are given in parentheses)

\begin{tabular}{|c|c|c|c|c|}
\hline & \multicolumn{2}{|c|}{ Group A } & \multicolumn{2}{|c|}{ Group B } \\
\hline & Men & Women & Men & Women \\
\hline $\begin{array}{l}\text { No of subjects } \\
\text { Age (a) } \\
\text { Height }(\mathrm{m}) \\
\text { Weight }(\mathrm{kg})\end{array}$ & $\begin{array}{c}4(3) \\
34 \cdot 2 \\
1 \cdot 76 \\
71 \cdot 0\end{array}$ & $\begin{array}{c}5(5) \\
32 \cdot 8 \\
1 \cdot 60 \\
59 \cdot 2\end{array}$ & $\begin{array}{c}3(2)_{+}^{+} \\
32 \cdot 3 \\
1 \cdot 72 \\
73 \cdot 8\end{array}$ & $\begin{array}{c}3(0)+ \\
36 \cdot 3 \\
1 \cdot 55 \\
57 \cdot 4\end{array}$ \\
\hline 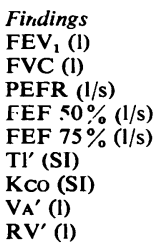 & $\begin{array}{l}A M \\
3 \cdot 39 \\
4 \cdot 14 \\
8 \cdot 58 \\
4 \cdot 29 \\
1 \cdot 63 \\
8 \cdot 7 \\
1 \cdot 79 \\
5 \cdot 55 \\
1 \cdot 58\end{array}$ & $\begin{array}{l}P M \\
3 \cdot 23^{*} \\
3.90^{*} \\
8 \cdot 57 \\
4 \cdot 07 \\
1 \cdot 35+ \\
8 \cdot 5 \\
1 \cdot 71 \\
5 \cdot 78 \\
1 \cdot 79+\end{array}$ & $\begin{array}{l}A M \\
3 \cdot 31 \\
3 \cdot 81 \\
8 \cdot 17 \\
5 \cdot 33 \\
2 \cdot 07 \\
8 \cdot 2 \\
1 \cdot 91 \\
4 \cdot 24 \\
1 \cdot 41\end{array}$ & $\begin{array}{l}P M \\
3 \cdot 29 \\
3 \cdot 76 \\
8 \cdot 89 \\
5.52 \\
2 \cdot 15 \\
8 \cdot 1 \\
1 \cdot 80 \\
4 \cdot 50 \\
1 \cdot 47\end{array}$ \\
\hline
\end{tabular}

${ }^{p} \mathrm{p}<0.01 . \dagger \mathrm{p}<0.05$. $¥$ One subject declined to give blood for this test.

$\mathrm{SI}$ for $\mathrm{Tl}=\mathrm{mmol} / \mathrm{min} / \mathrm{kPa}$ and for $\mathrm{KCO}=\mathrm{mmol} / \mathrm{min} / \mathrm{kPa} / \mathrm{l}$. 
flow rate after $50 \%$ vital capacity had been expired, the transfer factor, or the KCO. The group B subjects did not show significant changes for any of the tests. During the evening three subjects, all from group A, phoned from home to report that they had developed symptoms. The next morning a further ten (five from each group) reported that they had also had symptoms. The lung function changes during the Monday in all these subjects resembled those of the other members of their respective groups.

The following afternoon (Tuesday) the ventilatory measurements were repeated in eight subjects, seven in group A and one in group B. Among the former, compared with the previous morning the $\mathrm{FEV}_{1}$ and FVC were still significantly reduced. Measurements of transfer factor and single breath residual volume were repeated on five subjects. In all the transfer factor was lower by, on average, $1.2 \mathrm{mmol} /$ $\mathrm{min} / \mathrm{kPa}$ compared with the previous morning; the residual volume was still increased. Compared with the Monday afternoon, the Tuesday results were not significantly different. The alveolar volume remained relatively constant over the whole period.

On a Monday four weeks later, after a weekend in which the building was ventilated continuously, the measurements of ventilatory capacity were repeated. On this occasion none of the subjects reported symptoms during the evening but the next day eight (six from group A, two from group B) gave a positive report; on this occasion there were no significant changes in peak expiratory flow rate, FEV 1 , or FVC over the working day. Transfer factor and residual volume were not measured.

\section{Discussion}

The occurrence among a group of office workers of infrequent, transient evening malaise with fever, aching limbs, and polyuria went unrecognised for some time before the increasing severity of symptoms in some subjects led to the present investigation. This produced evidence for an immunological response to components of the humidifier sludge. The clinical manifestations were fever and malaise, which were usually mild, but in some subjects on repeated exposure became progressively very severe. As judged, however, by the proportion of group A subjects developing symptoms on the two test Mondays there was no clear relationship of symptoms to the atmospheric concentration of microorganisms. In addition no pyrogenic material was found in the collected air-borne dust from the office, ${ }^{5}$ and the total dust concentrations were very low. This is evidence both that some subjects became highly sensitised and the respiratory responses were not a reflex consequence of particles stimulating irritant receptors in the airways. ${ }^{\text {cf8 } 8}$ Indeed, the respiratory symptoms were mild in relation to the constitutional disturbance and polyuria; the occurrence of the latter is so far unexplained. Possibly, had a subject been exposed to a higher concentration of antigen by, for example, cleaning out the humidifier a more severe respiratory reaction might have developed; in this event the changes in lung function might have been more pronounced.

The physiological changes were detected only in subjects who, as a result of the independent clinical assessment, were considered to have developed the characteristic episodes at some time (group A). All but one of these subjects had serological evidence of sensitisation and in six the reaction was rated as strongly positive. ${ }^{4}$ The change in lung function took the form of a $6 \%$ reduction in FEV 1 and FVC (respectively $5.6 \%$ and $6.3 \%$ ) and a small but significant reduction in FEF $75 \%$ over a working Monday after a weekend when the heating was on but the windows and internal doors were shut. There was no change in group B subjects who experienced symptoms that did not conform to the pattern, although at least two were weakly sensitised against the antigen. The reduction in FVC was accompanied by an equivalent increase in residual volume, so there was no change in total lung capacity; there was also no change in PEFR. These findings are evidence for narrowing of small lung airways without affecting the larger airways. That the narrowing might have been due to a constituent of humidifier sludge is suggested by its occurrence at a time of planned exposure but not on another occasion when the building was ventilated and the exposure was almost certainly less; the concentrations of antigenic material were too low to be recorded, but the counts of Thermoactinomyces vulgaris, which were used as a marker, were respectively about 700 and 80 per $\mathrm{m}^{3}$.

The transfer factor of the lung for carbon monoxide and the Kco were normal and equal on the morning and afternoon of the day of exposure to the allergen but were on average $13 \%$ lower the next afternoon in the five subjects who agreed to be remeasured. These subjects were then asymptomatic and had normal chest radiographs. The ambient temperature was higher by $3.5^{\circ} \mathrm{C}$, however, and this by itself could explain the difference. ${ }^{9}$

Due to the circumstances of the study no physiological measurements were made on the present subjects during the period of maximal symptoms, which was on average about 13 hours after the start of exposure. Thereafter the investigation was terminated by the reconstruction of the office block and by the reluctance of all parties to participate in inhalation challenge. Thus the findings are inevitably incomplete. Nevertheless, they show that among 
subjects sensitised against one or more strain of acanthamoeba there is an identifiable syndrome characterised by fever malaise, myalgia, polyuria, and some impairment of lung function. Respiratory symptoms are not a prominent feature. The extent of the impairment in lung function cannot be deduced precisely from the present evidence, but in the prodromal phase the change is small and affects the small airways to a greater extent than the gasexchanging part of the lung. The emerging picture apparently differs in detail from that reported by Friend $e t a l,{ }^{2}$ but more evidence is needed. Some will be provided by the study of hospital operating theatre staff $^{3}$ now in progress.

We are indebted to Dr A Jones of the Employment Medical Advisory Service, who with $\operatorname{Dr} M$ Jones introduced us to this problem; to Dr J C Gilson, who co-ordinated the plans for its investigation; and to Dr JH Edwards and Mr J WSkidmore who undertook the immunological studies and environmental sampling respectively. The investigation was made possible through the active co-operation of management and staff of the factory where the episode occurred.

\section{References}

${ }^{1}$ Fink JN, Banaszak EG, Barboriak JJ, et al. Interstitial lung disease due to contamination of forced air systems. Ann Intern Med 1976;84:406-18.

${ }^{2}$ Friend JAR, Gaddie J, Palmer KNV, Pickering CAC, Pepys J. Extrinsic allergic alveolitis and contaminated cooling water in a factory machine. Lancet 1977 ; $\mathrm{i}: 297$ 300.

${ }^{3}$ Campbell IA, Cockcroft AE, Edwards JH, Jones $M$. Humidifier fever in an operating theatre. $\mathrm{Br}$ Med J 1979; ii:1036-7.

${ }^{4}$ Edwards JH. Humidifier fever. Thorax 1977;32:657.

${ }^{5}$ Edwards $\mathrm{JH}$. Microbial and immunological investigations after an outbreak of humidifier fever. Br J Ind Med 1980; 37:55-62.

- McDermott M, McDermott TJ. Digital incremental techniques applied to spirometry. Proc R Soc Med 1977; 70:169-71.

${ }^{7}$ Cotes JE. Lung function. Assessment and application in medicine. 4th ed. Oxford: Blackwell Scientific Publications, 1979.

${ }^{8}$ Widdicombe JG. Reflexes from the lungs in the control of breathing. In: Linden $\mathrm{RJ}$, ed. Recent advances in physiology. 9th ed. Edinburgh: Churchill, Livingstone, 1974:239-78.

${ }^{9}$ Newman F. The effects of exercise posture and ambient temperature on ventilation and diffusion in the human lung. University of London, 1962. (PhD thesis.) 